\title{
Vitória da tradição ou resistência da inovação: o Ensino de História entre a BNCC, o PNLD e a Escola
}

\section{Victory of tradition or resistance of innovation: the teaching of history between the BNCC, the PNLD and the School}

\author{
Sandra Regina Ferreira de Oliveira* \\ Flávia Eloisa Caimi**
}

\begin{abstract}
RESUMO
Assentadas na premissa de que entre o currículo prescrito, o currículo editado e o currículo em ação ocorrem aproximações e distanciamentos cujos contornos escapam a quaisquer formas de controle prévio, debruçamonos, neste estudo, sobre a Base Nacional Comum Curricular (BNCC), o Programa Nacional do Livro e do Material Didático (PNLD) e os contextos escolares em que se efetivam tais políticas curriculares. A abordagem se caracteriza como pesquisa bibliográfica e documental, em que se focaliza especificamente o componente curricular História nos Anos Finais do Ensino Fundamental. Os resultados permitem concluir que a versão homologada da BNCC guarda estreitas relações com a tradição historiográfica que privilegia uma abordagem cronológica, linear, quadripartite/tripartite e eurocêntrica. Ao adotar como um dos procedimentos básicos a identificação dos eventos considerados importantes na história do ocidente, obstaculiza-se o acesso a outras estratégias de seleção e organização do conhecimento histórico. O PNLD, por sua vez, parece assumir o papel de guardião do currículo prescrito na BNCC, zelando pela oferta de livros e materiais didáticos que tendem a impor aos professores e estudantes uma matriz de referência
\end{abstract}

*Universidade Estadual de Londrina. Londrina, Paraná, Brasil. E-mail: sandraoliveira.uel@ gmail.com - https://orcid.org/0000-0002-9777-4461

** Universidade de Passo Fundo. Passo Fundo, Rio Grande do Sul, Brasil. E-mail: caimi@ upf.br - https://orcid.org/0000-0001-5509-6060 
descontextualizada da realidade da escola, reduzindo possibilidades de construções coletivas frente às singularidades locais e regionais. Contudo, é no currículo em ação, no cotidiano da escola, nas práticas de seus principais atores, que reside o impulso da criação, da inovação e da resistência.

Palavras-chave: BNCC. PNLD. Escola. História. Currículo.

\begin{abstract}
Based on the premise that between the prescribed curriculum, the edited curriculum and the curriculum in action occur approximations and distances whose contours escape any form of prior control, we focus, in this study, on the Base Nacional Comum Curricular [National Common Curriculum Base] (BNCC), the Programa Nacional do Livro e do Material Didático [National Book and Teaching Material Program] (PNLD) and the school contexts in which such curricular policies are carried out. The approach is characterized as bibliographic and documentary research, in which it focuses specifically on the curricular component History in the Final Years of Elementary School. The results allow us to conclude that the homologated version of BNCC has close relations with the historiographical tradition that favors a chronological, linear, quadripartite/tripartite and eurocentric approach. By adopting as one of the basic procedures the identification of events considered important in the history of the west, it impedes access to other strategies of selection and organization of historical knowledge. The PNLD, in turn, seems to assume the role of guardian of the curriculum prescribed at BNCC, ensuring the supply of books and teaching materials that tend to impose on teachers and students a reference matrix decontextualized of the school reality, reducing possibilities for collective constructions in the face of local and regional singularities. However, it is in the curriculum in action, in the daily life of the school, in the practices of its main actors, that lies the impulse of creation, innovation and resistance.
\end{abstract}

Keywords: BNCC. PNLD. School. History. Curriculum.

\title{
Introdução
}

Em 20 de dezembro de 2017, por meio da Resolução $\mathrm{CNE} / \mathrm{CP}^{\circ}$ 2, a Base Nacional Comum Curricular (BNCC) foi homologada no Brasil. Conforme divulgado no portal do Ministério da Educação (MEC), ela deve "ser respeitada obrigatoriamente ao longo das etapas e respectivas modalidades no âmbito da Educação Básica" (BRASIL, 2017a). Ali também é anunciado que caberá ao 
Conselho Nacional de Educação realizar as tratativas para a sua implementação e se disponibiliza nove documentos que compõem o processo, "desde a chegada da BNCC ao Conselho Nacional de Educação até a publicação da Resolução" (BRASIL, 2017a).

No ano seguinte à Resolução, o MEC veiculou propaganda (BRASIL, 2018a) na grande mídia nacional, mostrando crianças das cinco regiões brasileiras que, a partir de seus lares, se preparam e se dirigem à escola. No texto, narrado em concomitância com as imagens, afirma-se:

O Brasil terá, pela primeira vez, uma Base Nacional Comum Curricular! $\mathrm{O}$ documento é democrático e respeita as diferenças. Com a Base, todos os estudantes do país, de escolas públicas ou particulares, terão os mesmos direitos de aprendizagem. [A aula começa e o/a professor/a fala] Hoje a aula é sobre cidadania. [O narrador prossegue] Isso é bom. Se a base da educação é a mesma, as oportunidades também serão (BRASIL, 2018a).

Nessa propaganda, em pouco mais de 30 segundos, o Ministério da Educação expõe, claramente, o quão distante está da escola real. No conjunto da obra, as imagens, os personagens e o texto remetem às representações sobre escolas, alunos, famílias, professores, sala de aula, conteúdo, currículo, aprendizagem, transporte escolar, que retratam as concepções nas quais, em síntese, alicerça a ideia de obrigatoriedade da BNCC, em sua versão final. Tal documento se apresenta para a sociedade como a régua homogeneizadora, com poderes de equalizar as profundas diferenças que assolam o Brasil. A forma como a BNCC foi relatada via mídia, com o objetivo de transmitir uma mensagem para a população leiga, é um campo a parte a ser estudado, cujos resultados desvelam concepções e enriquecem o pensar sobre a escola pública brasileira (BRESSANIN, 2018).

O que a publicidade do MEC (BRASIL, 2018a) não revela é que a construção da BNCC foi travada em meio a uma arena conflagrada, o que é salutar, visto que um dos poucos consensos possíveis no âmbito da literatura especializada é o conceito de currículo como um campo de constante disputa. No entanto, compreender o currículo nessa perspectiva, em se tratando do Brasil pós-2016, é temática que se amplia para além do âmbito educacional e, nesse sentido, a história de construção da BNCC é marcada por sutis rupturas diante do Estado democrático. A aprovação do documento em 2017, de forma aligeirada, sem a parte correspondente ao Ensino Médio, e sem considerar solicitações de diversos setores para ampliação do debate, retrata que no decorrer dos anos a 
concepção do que deveria ser uma base nacional comum foi se distanciando do previsto na Constituição Federal (BRASIL, 1988), na Lei de Diretrizes e Bases da Educação Nacional (BRASIL, 1996), no Plano Nacional de Educação (BRASIL, 2014) e nas Diretrizes Curriculares Nacionais, culminando com a elaboração de um documento curricular prescritivo, definidor de conteúdos a serem ensinados e competências a serem desenvolvidas, ainda que o MEC entenda e defenda que a BNCC não é currículo (AGUIAR, 2018).

Podemos afirmar, na esteira do anunciado por Alice Casimiro Lopes (2018), quão significativo foi o volume de documentos que normatizaram a questão curricular no Brasil nas últimas décadas. Ao retomar a história da construção de cada um deles, deparamo-nos com cenários de intensas lutas, acompanhadas de constantes acordos, e assim prosseguíamos escrevendo a história da educação escolar brasileira. Ocorre que, após 2016, a sociedade democrática que supúnhamos ser, um berço para lutas-acordos-lutas-acordos, foi alterada radicalmente com a destituição da presidenta eleita. O que se desenhou no país, a partir de então, é uma luta sem possibilidade de acordos, pois estamos a operar com grupos que se definem detentores de verdades absolutas em torno de vários assuntos, inclusive sobre o que é uma escola, como e o que deve ser ensinado nesse lugar.

É a partir desse contexto que tecemos a abordagem sobre a Base Nacional Comum Curricular, com recorte definido para o componente curricular História destinado aos Anos Finais do Ensino Fundamental. Objetivamos abordar as especificidades que identificamos na BNCC a partir do conceito de currículo (prescrito, editado e em ação) em estreita relação com o Programa Nacional do Livro e do Material Didático (PNLD). A escolha pelo PNLD se justifica pelo fato de que essa política pública atravessou a elaboração dos documentos curriculares citados e deles recebeu aportes que definiram e redefiniram os diversos editais que normatizaram a produção dos livros didáticos no país nas últimas décadas.

O livro didático também pode ser compreendido como uma orientação curricular, uma vez que nele se materializam as prescrições curriculares, como afirmam Franco, Silva Junior e Guimarães (2018, p. 1028):

O primeiro edital do PNLD da "era da Base" foi publicado em julho de 2017, ou seja, antes da homologação da BNCC que ocorreu em 20 dezembro de 2017, constrangendo autores e editores a (re)elaborarem, adaptarem as coleções, de acordo com um Documento de política pública em processo de elaboração e discussão. 
Ainda, segundo os autores,

[...] a BNCC cumpre um papel radical de regulação externa, pois determina o que será ensinado (os conteúdos), como será ensinado (as metodologias), quando (a ordenação do tempo escolar), o que e como será avaliado, enfim o que deve e pode ser ensinado e aprendido (FRANCO; SILVA JUNIOR; GUIMARÃES, 2018, p. 1032).

A abordagem metodológica adotada nesta pesquisa recai sobre estudos bibliográficos e análise de documentos, em especial a BNCC da área de História para os Anos Finais do Ensino Fundamental, o Edital PNLD 2020 e o Guia de Livros Didáticos PNLD 2020, do componente curricular História.

A estrutura do artigo se constitui de quatro seções, além desta primeira em que é apresentada a introdução. Na segunda seção explicitamos o conceito de currículo prescrito e, tomando por referência o documento da BNCC da área de História para os Anos Finais do Ensino Fundamental, destacamos as principais proposições e intentamos apontar o que é novo em relação à tradição pedagógica e historiográfica. Na terceira seção, tendo por eixo o conceito de currículo editado, estabelecemos uma análise cotejada entre o constante na BNCC e no PNLD, tomando o Edital e o Guia de Livros Didáticos do PNLD 2020 - Área de História, como documentos base. Na sequência, constituindo a quarta seção, discorremos sobre o currículo em ação, dispondo-nos a compreender quais perspectivas podem ser anunciadas para a concretização da proposta da BNCC no cotidiano das escolas. Finalizamos a abordagem com a quinta seção, intitulada Indignações finais, na qual expomos preocupações com as políticas públicas atuais que, em nosso entendimento, dilapidam os poucos avanços que a sociedade brasileira conseguiu conquistar, a duras penas, com relação à escola pública. Por outro lado, também usamos o fio da esperança para tecer o amanhã, pois aprendemos com Paulo Freire (2011, p. 11) que "nas situações-limite, mais além das quais se acha o 'inédito viável', às vezes perceptível, às vezes, não, se encontra razões de ser para ambas as posições: a esperançosa e a desesperançosa”. 


\section{Caminhos do currículo prescrito: um olhar para a BNCC}

Em seus estudos, Sacristán (2013a) anuncia uma visão processual de currículo que contempla três planos principais: os fins, objetivos ou motivos; as ações e atividades; e os resultados ou efeitos reais do projeto educacional. Tais planos se desdobram em diversas dimensões, como currículo oficial/prescrito, currículo interpretado, currículo realizado, currículo recepcionado, currículo avaliado. Ainda se pode falar em currículo editado (BENITO, 2016), currículo nulo (MEZA; CEPEDA, 2001), currículo oculto (SILVA, 2010).

Dentre essas inúmeras formas de conceber e abordar o tema do currículo, nesta seção nos deteremos no documento denominado Base Nacional Comum Curricular, entendido como expressão de um projeto de educação para a nação brasileira, com função normativa e reguladora. Como texto curricular visível (SACRISTÁN, 2013a), este projeto tem sido denominado de currículo idealizado, currículo explicitamente almejado, currículo oficial, currículo formal, currículo prescrito.

A BNCC brasileira consiste em um documento de 600 páginas, estruturado em cinco partes, assim nomeadas (BRASIL, 2017b): Introdução, Estrutura da BNCC, Etapa da Educação Infantil, Etapa do Ensino Fundamental, Etapa do Ensino Médio. Nosso foco de estudo recai sobre os itens (4.4.2.) História; Competências específicas de História para o Ensino Fundamental (BRASIL, 2017b, p. 397-402); (4.4.2.2.) História no Ensino Fundamental - Anos Finais: unidades temáticas, objetos de conhecimento e habilidades (BRASIL, 2017b, p. 416-433).

Neste corpus, buscamos destacar as principais proposições relativas aos saberes históricos selecionados e às operações cognitivas ensejadas, no esforço de apontar o que pode ser caracterizado como inovação, em relação aos pressupostos historiográficos e pedagógicos vigentes no campo do Ensino de História. Aqui nos valemos da premissa trazida por Sacristán (2013b, p. 27), quando afirma que todo o texto curricular, embora traduzido, interpretado, assumido ou subvertido pelos leitores, "é importante, à medida que difunde os códigos sobre o que deve ser a cultura nas escolas, tornando-os públicos". Vejamos, então, que códigos são anunciados para a história escolar nos Anos Finais do Ensino Fundamental.

Primeiramente, no horizonte de um ideário positivo, identificamos os pressupostos teórico-metodológicos que orientam a proposta dos objetos de conhecimento e das habilidades. Ainda que não sejam nomeados dessa forma no texto curricular, encontramos os seguintes pressupostos de formação histórica: (1) a relação passado-presente é orientadora da dinâmica do ensino-aprendizagem, privilegiando-se um passado que dialogue com o tempo atual (BRASIL, 2017b, p. 397); (2) a História é entendida como construção e disputa pelo sentido, "ela é a correlação de forças, de enfrentamentos e da batalha para a produção de 
sentidos e significados, que são constantemente reinterpretados por diferentes grupos sociais e suas demandas" (BRASIL, 2017b, p. 397); (3) sobre a narrativa histórica, defende-se que um objeto só se torna documento quando um narrador lhe confere sentido e, através dele, expressa a dinâmica da vida das sociedades (BRASIL, 2017b, p. 397); (4) o tratamento da História se faz com diferentes fontes e tipos de documentos, pois "os registros e vestígios deixados pelos indivíduos [...] carregam em si mesmos a experiência humana" (BRASIL, 2017b, p. 398); (5) a dinâmica do estudo da história é concebida em círculos concêntricos $-\mathrm{Eu}$, Outro, Nós -, iniciando pelo sujeito, ampliando-se para o outro (diferente ou semelhante), seguindo para outros povos e, finalmente, para o mundo (BRASIL, 2017b, p. 398); (6) a capacidade de comunicação, diálogo e argumentação constitui ferramenta para lidar respeitosamente com a pluralidade, para enfrentar problemas, tensões e conflitos, para superar contradições do mundo vivido (BRASIL, 2017b, p. 398); (7) o trabalho com a história pode levar estudantes e professores a desenvolver "atitude historiadora" e a produzir conhecimento em âmbito escolar (BRASIL, 2017b, p. 398); (8) as operações cognitivas para estimular o pensamento histórico compreendem "os processos de identificação, comparação, contextualização, interpretação e análise de um objeto" (BRASIL, 2017b, p. 399); (9) a pluralidade e a diversidade cultural figuram especialmente nas abordagens relacionadas à história dos povos indígenas originários $\mathrm{e}$ africanos (BRASIL, 2017b, p. 401).

A efetivação destes pressupostos de formação histórica dos estudantes ocorreria mediante três procedimentos básicos: (a) pela identificação dos eventos considerados importantes na história do Ocidente, ordenados de forma cronológica e localizados no espaço geográfico; (b) pela seleção, compreensão e reflexão sobre os significados da produção, circulação e utilização de documentos (materiais ou imateriais); (c) pela interpretação de diferentes versões de um mesmo fenômeno, com vistas à elaboração de proposições próprias (BRASIL, 2017b, p. 417).

O que se pode depreender até aqui é que esta terceira versão da BNCC guarda estreitas relações com a tradição historiográfica que privilegia uma abordagem cronológica, linear, justaposta, do passado para o presente, quadripartite/tripartite, eurocêntrica. Ainda que anuncie que a relação passado-presente é orientadora do estudo, ao adotar como um dos procedimentos básicos a identificação dos eventos considerados importantes na história do ocidente, de forma cronológica e linear, acaba por restringir outras possibilidades de seleção e organização do conhecimento histórico, fortalecendo uma perspectiva eurocentrada. Esta normativa fica mais clara quando se estende o olhar para as unidades temáticas e objetos de conhecimento, que se resumem a uma tábua de conteúdos muito assemelhada ao sumário de livros didáticos de décadas anteriores. 
Nesta versão da BNCC prevalece a ambição de estudar toda a história, das cavernas ao terceiro milênio, ou das origens do homem à era digital, parafraseando o título de conhecidas coleções didáticas. Não se visualiza nenhuma operação de recorte e seleção dos conteúdos, que abra espaço para outras possibilidades temáticas e interpretativas. Isso é exposto textualmente no documento curricular, quando se anuncia a perspectiva cronológica como forma privilegiada de registro de memória e a "seleção dos eventos históricos consolidados na cultura historiográfica contemporânea" (BRASIL, 2017b, p. 416).

O tratamento da chamada "diversidade cultural" se desenvolve na mesma direção, priorizando abordagens etnocêntricas, heteronormativas, do homem branco. Não obstante o cumprimento da legislação relativa à educação para as relações étnico-raciais, notadamente as Leis 10.639/2003 (BRASIL, 2003) e 11.645/2008 (BRASIL, 2008), o texto curricular anuncia claramente o lugar de apêndice que os povos indígenas, africanos e afrodescendentes ocupam no curso da história ocidental:

A relevância da história desses grupos humanos reside na possibilidade de os estudantes compreenderem o papel das alteridades presentes na sociedade brasileira, comprometerem-se com elas e, ainda, perceberem que existem outros referenciais de produção, circulação e transmissão de conhecimentos, que podem se entrecruzar com aqueles considerados consagrados nos espaços formais de produção de saber (BRASIL, 2017b, p. 401).

Se são "outros referenciais" que se entrecruzam com os "consagrados", trata-se de uma abordagem que não é a principal.

No que respeita às discussões de gênero, essas compõem o chamado currículo nulo, ou seja, estão ausentes da proposta curricular da História. Ao fazer a busca pelo descritor "gênero", visualiza-se mais de 400 ocorrências ao longo das 600 páginas da BNCC. Todavia, essas ocorrências tratam de gêneros textuais, discursivos, literários, artísticos, orais, escritos, digitais, epistolares, jornalísticos, narrativos, secundários, multissemióticos, hipermidiáticos, normativos, narrativos, musicais, dentre outros. Na proposta de História para os Anos Finais do Ensino Fundamental consta apenas duas menções à temática da mulher na história, uma no sexto ano, apontando "O papel da mulher na Grécia e em Roma, e no período medieval” (BRASIL, 2017b, p. 420) e outra no nono ano, que propõe o estudo do "Anarquismo e protagonismo feminino" (BRASIL, 2017b, p. 428). Referências às populações LGBTQIA+ ou proposições de 
combate à violência de gênero também estão praticamente ausentes na proposta de História, localizando-se apenas uma menção no $9^{\circ}$ ano, ao apresentar a habilidade EF09HI26 (BRASIL, 2017b, p. 431).

Na estruturação da BNCC, propõe-se uma correlação direta entre os objetos de conhecimento e as habilidades a serem desenvolvidas, por meio de códigos. Sabe-se que esta proposição cumpre a função de respaldar o currículo editado (livro didático) e o currículo avaliado (testes padronizados, Enem etc.). A cada objeto de conhecimento corresponde uma habilidade, de modo que no $6^{\circ}$ ano constam 19 habilidades, no $7^{\circ}$ ano 17 , no $8^{\circ}$ ano são 27 habilidades e no $9^{\circ}$ ano são 36. Buscamos analisar quais operações cognitivas essas 99 habilidades requerem dos estudantes, ao longo dos quatro anos que compõem os Anos Finais do Ensino Fundamental.

TABELA 1 - HABILIDADES REQUERIDAS DOS ESTUDANTES NOS ANOS FINAIS DO ENSINO FUNDAMENTAL ${ }^{1}$

\begin{tabular}{cccccc}
\hline HABILIDADES & $6^{\circ}$ ano & $7^{\circ}$ ano & $8^{\circ}$ ano & $9^{\circ}$ ano & TOTAL \\
\hline Identificar & 7 & 5 & 13 & 13 & 38 \\
Analisar & 1 & 4 & 2 & 5 & 12 \\
Descrever & 3 & 3 & & 5 & 11 \\
Discutir & 1 & 1 & 2 & 6 & 10 \\
Caracterizar & 2 & 2 & 2 & 2 & 8 \\
Relacionar & - & - & 1 & 4 & 5 \\
Explicar & 1 & 1 & 1 & - & 3 \\
Conhecer & 1 & - & 2 & - & 3 \\
Comparar & - & 1 & - & 1 & 2 \\
Reconhecer & - & - & 1 & - & 1 \\
Conceituar & 1 & - & - & - & 1 \\
Diferenciar & 1 & - & - & - & 1 \\
Associar & 1 & - & - & - & 1 \\
Estabelecer relações causais & - & - & 1 & - & 1 \\
Formular questionamentos & - & - & 1 & - & 1 \\
Aplicar & - & - & 1 & - & 1 \\
\hline TOTAL & 19 & 17 & 27 & 36 & 99 \\
\hline
\end{tabular}

FONTE: Elaboração das autoras a partir da BNCC (BRASIL, 2017b).

1 Necessário esclarecer que nos detivemos no primeiro verbo de cada habilidade, desconsiderando as situações em que dois verbos são indicados na mesma habilidade, como identificar e analisar, ou descrever e discutir, por exemplo. 
Note-se que as habilidades predominantemente requeridas dos estudantes são aquelas que propiciam operações cognitivas de menor complexidade, como identificar, descrever, caracterizar, que totalizam 57 dentre os 99 requerimentos. Além dessas, comparecem habilidades um tanto genéricas, como discutir, conhecer, reconhecer (14 ocorrências). Habilidades que exigem operações de pensamento mais sofisticadas, como analisar, relacionar, explicar, comparar, conceituar, diferenciar, associar, estabelecer relações causais, formular questionamentos e aplicar, têm reduzida presença no conjunto das habilidades, compondo apenas 28 ocorrências, menos de um terço do total. Encerramos esta seção afirmando nosso entendimento de que a proposta curricular prescrita na BNCC se configura naquilo que Sacristán (2013b, p. 27) denomina um texto regressivo, que "sequer diz aos 'leitores' algo sobre uma 'terra prometida', mas se limita a reafirmar a tradição 'tradicional' - a expressão é válida, pois também há tradições de progresso". A questão agora é verificar que efeitos este texto regressivo pode ter no currículo editado e no currículo em ação, tarefa a que nos dedicaremos nas duas seções subsequentes.

\section{Caminhos do currículo editado: um olhar para o PNLD}

Por muitas décadas, até a homologação da BNCC, o livro didático ocupou o lugar de currículo editado, na ausência de um currículo oficial nacional. De acordo com Benito (2016, p. 45, tradução nossa), o livro didático, ainda que não configure todo o programa escolar, é uma forma de materialização do currículo editado, "a versão impressa da vulgata em que se traduz o currículo normativo e a proposta de conhecimentos e ações que orientam a prática de ensino em um grande número de escolas".

Mediante esta acepção, focalizaremos nosso olhar em dois documentos basilares do Programa Nacional do Livro Didático e do Material Didático - o Edital de Convocação do PNLD 2018, Anos Finais do Ensino Fundamental (BRASIL, 2018b) e o Guia de Livros Didáticos PNLD 2020: História (BRASIL, 2019) -, no intuito de analisar como o currículo prescrito na BNCC é operado no âmbito do PNLD, ensejando assim o currículo editado no Livro Didático de História.

No Edital do PNLD 2020 (BRASIL, 2018b) consta cerca de 30 menções à Base Nacional Comum Curricular, evidenciando a expectativa de total alinhamento entre os documentos. Em inúmeros excertos do Edital fica estabelecido que o livro didático será avaliado em consonância com as 
competências e habilidades definidas na $\mathrm{BNCC}$, e que serão excluídas as obras didáticas que, dentre outros critérios, não apresentarem uma "abordagem capaz de contribuir para o alcance dos objetos de conhecimento e respectivas habilidades dispostos na BNCC" (BRASIL, 2018b, p. 39). É determinado, ainda, que "as obras devem zelar, particularmente, pela presença e pela forma de abordagem dos objetos de conhecimento alinhados às habilidades de cada componente curricular ali presentes" (BRASIL, 2018b, p. 42). Ressalva-se, textualmente, que as unidades temáticas da Base não devem necessariamente servir como critério para a elaboração da obra, entretanto, paradoxalmente, obriga-se a "contemplar todos os objetos de conhecimento e habilidades constantes na BNCC" (BRASIL, 2018b, p. 42). Na mesma direção, as orientações anunciadas no início de cada volume do Livro do Aluno e no Manual do Professor devem, dentre outros, "explicitar a correspondência do conteúdo com os objetos de conhecimento e habilidades da BNCC" (BRASIL, 2018b, p. 43).

No Guia de Livros Didáticos do PNLD 2020 - História (BRASIL, 2019), referente aos Anos Finais do Ensino Fundamental, localizamos 136 menções ao documento da BNCC. Longo trecho do Guia é ocupado com a reprodução do Edital, ressaltando essa estreita vinculação entre a BNCC e o PNLD. Enfatizase veementemente que serão excluídas as obras que não contemplarem todos os objetos de conhecimento e que não contribuírem adequadamente para o desenvolvimento de todas as competências gerais e específicas constantes na BNCC. Também é elucidativa desta vinculação a reprodução da ficha de avaliação, que contém 47 páginas e apresenta um extenso checklist cujo sentido é verificar a compatibilidade entre a BNCC e a coleção didática inscrita para avaliação. Neste empreendimento, cada item, cada unidade temática, cada legislação, cada objeto de conhecimento e respectivo código de habilidade constante no texto da Base, é contrastado com os livros didáticos avaliados.

$\mathrm{O}$ que se conclui desta íntima relação estabelecida entre o currículo prescrito e o currículo editado é a preparação de um terreno fértil para o currículo avaliado, especialmente no contexto da avaliação em larga escala. O poder regulador desta política curricular vai muito além do propósito de estabelecer um projeto de educação nacional, na medida em que se mostra gerencialista, homogeneizante e servil aos processos avaliativos externos. Os materiais didáticos, dessa forma, promovem uma espécie de ponte entre o currículo prescrito e o currículo avaliado, que tendem a impor aos professores e estudantes uma matriz de referência descontextualizada da realidade da escola, reduzindo possibilidades de construções coletivas frente às singularidades locais e regionais, às culturas, identidades, subjetividades e demandas comunitárias (HYPOLITO, 2010). 
No texto do Guia de Livros Didáticos do PNLD 2020 consta observações em que os avaliadores sinalizam, de forma sutil ou explícita, os limites da vinculação entre as duas políticas curriculares. Com relação à ênfase nos objetos de conhecimento (conteúdos), ressalva-se que estes só ganham sentido se provocarem reflexões com o tempo presente e contribuírem para tomadas de decisões autônomas, justas e éticas (BRASIL, 2019). Ainda, convidam o professor a "interferir na cronologia e nos fatos históricos selecionados na coleção, de acordo com o que lhe parecer adequado e necessário, mantendo-se em consonância com a proposta da BNCC" (BRASIL, 2019, p. 6). Sobre o predomínio de habilidades de menor complexidade, como a identificação e a descrição, enfaticamente presentes nas atividades e nas propostas avaliativas das coleções, alertam o professor sobre a necessidade de extrapolar os limites da memorização de informações e alargar os marcos tradicionais da disciplina (BRASIL, 2019). Os avaliadores denunciam também a acanhada presença, nas coleções, das "habilidades de discutir conceitos, comparar e diferenciar, confrontar diferentes interpretações históricas, avaliar impactos de um processo ou acontecimento histórico" (BRASIL, 2019, p. 26).

A noção de tempo, por sua vez, resumida à dimensão cíclica e linear no texto curricular, precisa ser enfrentada pelo docente como categoria complexa, experiência social e cultural que tem sua centralidade no sujeito (BRASIL, 2019). Nessa direção, alertam o professor sobre as concepções quadripartite/tripartite que orientam a história europeia/brasileira, respectivamente, e o seu caráter marcadamente eurocêntrico, características preponderantes nas coleções didáticas do PNLD 2020 (BRASIL, 2019). Nos temas relativos à história e cultura dos povos indígenas, africanos e afro-brasileiros, os avaliadores asseveram que as obras aprovadas "não conseguiram avançar no tratamento destas temáticas para além do que aquelas aprovadas em editais anteriores avançaram, impulsionadas pelas exigências das Leis $\mathrm{n}^{\circ} 10.639$, de 2003, e $\mathrm{n}^{\circ} 11.645$, de 2008" (BRASIL, 2019 , p. 23). Da mesma forma, quanto às temáticas de gênero, constatam o protagonismo masculino na abordagem dos processos históricos e o silenciamento das relações homoafetivas e seu significado ao longo da história (BRASIL, 2019).

Quando se analisa os dois documentos na mesma perspectiva, como realizado até aqui, não causa estranheza o fato de as coleções didáticas se manterem dentro dos parâmetros da tradição historiográfica e da cultura manualística que as vêm caracterizando há décadas, como currículo editado. Não é desta BNCC que se poderá esperar rupturas com os cânones disciplinares quase seculares, pois, como sinaliza Sacristán, no texto regressivo não há nem mesmo uma "carga utópica" (SACRISTÁN, 2013b, p. 24), nem sequer "uma terra prometida" (SACRISTÁN, 2013b, p. 27). Diante disso, o que podemos esperar do currículo em ação? Acreditando que o professor é um "mediador 
decisivo" (ACOSTA, 2013, p. 189) entre o currículo prescrito e o currículo real, como ele pode interpretar as partituras denominadas BNCC e Livro Didático?

\section{Caminhos do currículo em ação: um olhar para professores e estudantes na sala de aula}

Compreendemos currículo em ação, na esteira de Sacristán (1998, 2013a), como o que se efetiva do proposto, do interpretado, do executado na prática. Reconhecendo as propostas como pontos de partida, o autor destaca que é na ação, na prática, que o estabelecido nos documentos se torna realidade, se reveste de significado e assume um valor, por vezes, diferente do que o almejado pelos propositores.

Quais seriam as ações, os movimentos em sala de aula, caso a proposta para o Ensino de História nos Anos Finais do Ensino Fundamental se efetive? A considerar as ações apresentadas na Tabela 1, infere-se que a movimentação desejada aponta para professores e estudantes como sujeitos receptores de saberes e executores de ações cognitivamente pautadas na identificação, descrição e análise de algo já dado. O estabelecimento de relações causais e a formulação de questionamentos, por exemplo, são habilidades contempladas uma única vez. Esse é um ponto importante para se pensar as prioridades a partir das quais a BNCC, em sua terceira versão, foi elaborada. Para avançar nas hipóteses sobre o que podemos esperar do currículo em ação, em especial na área de História, e como o professor constituirá o seu fazer pedagógico sob a regência, ou não, da $\mathrm{BNCC}$ e do livro didático, convém, em poucas linhas, traçar um breve retrato acerca da situação na qual se encontravam os livros didáticos de História em 2016 e quais reverberações eram identificadas no cotidiano escolar.

Em que pese todas as críticas ao PNLD, dentre as quais a que remete à padronização de um formato de livro e de um saber a ser ensinado, é fato a mudança identificada nos livros didáticos de História na direção de uma sociedade mais plural, justa e includente. Também é fato a mudança nas atividades propostas que, com o passar dos anos, aproximaram o estudante de um papel mais protagonista na busca de saber, principalmente no trabalho de seleção e análise de fontes. O diálogo com o entorno, como as questões presentes no cotidiano, foi amplamente demandado por meio dos Editais e, ainda que com limitações, se fizeram presentes nos livros didáticos. Ano após ano, aos capítulos dos livros que em sua maioria apresentam a História aos estudantes a 
partir de vertentes quadripartite/tripartite e sem questionamentos, somaram-se "textos complementares", "projetos" e outras propostas que apontam para uma abordagem mais investigativa e questionadora da História.

Em ação no país, até 2016, também estavam as políticas públicas de incentivo à educação, sinalizando para horizontes promissores advindos do investimento dos recursos do pré-sal na formação de professores, nas escolas públicas, na produção de material didático, enfim, em todos os aspectos que são a base para uma educação de qualidade. Nas escolas, o que se concretizava como currículo em ação no campo da História era fortemente definido por meio dos conteúdos apresentados nos livros didáticos que eram escolhidos pelos professores em meio a um leque significativo de opções. Os problemas sempre foram muitos, os questionamentos, embates e disputas em torno dos conteúdos também. No tocante às avaliações em larga escala, especialmente com relação ao Programme for International Student Assessment [Programa Internacional de Avaliação de Estudantes] (PISA) ${ }^{2}$, os resultados dos estudantes não avançavam na velocidade desejada por aqueles que compreendem a melhoria da qualidade da educação sob o viés comparativo entre os países.

Em 2014, um grupo de professores convidados pelo MEC elaborou um documento que recebeu o título de "Direitos de Aprendizagem" com objetivo de atender à construção de uma proposta nacional de educação. Macedo $(2019$, p . 47) reconhece que "a opção por um currículo guiado por direitos de aprendizagem [...] foi uma demanda de movimentos acadêmicos e sociais com vistas a distanciar a proposta da linguagem da testagem".

Ocorre que, em meio aos acordos políticos que se sucederam após a eleição presidencial de 2014, estabeleceu-se uma direta relação entre a base nacional comum e as políticas de avaliação em larga escala. Após 2016 identifica-se maior aproximação e estabelecimento de parcerias com setores privados que já estavam em ação nas escolas, com variados projetos que, em sua maioria, operam com a lógica de oferecer propostas e materiais prontos para que os professores e alunos sigam os roteiros nos quais encontram-se pré-definidos os pontos de partida e os pontos de chegada quanto à construção do conhecimento, os chamados sistemas estruturados de ensino.

2 Trata-se de um estudo comparativo internacional realizado trienalmente pela Organização para a Cooperação e Desenvolvimento Econômico (OCDE), com vistas a oferecer informações sobre o desempenho de estudantes na faixa etária dos 15 anos. Tendo o Instituto Nacional de Estudos e Pesquisas Educacionais Anísio Teixeira (INEP) como órgão responsável pelo planejamento e a operacionalização da avaliação no Brasil, o estudo avalia três domínios - leitura, matemática e ciências - em todas as edições ou ciclos, além de avaliar os denominados "domínios inovadores", como Resolução de Problemas, Letramento Financeiro e Competência Global. 
Portanto, a ação do professor antes da promulgação da BNCC era desempenhada com certa autonomia quanto à escolha dos livros didáticos; à rotina de organização dos conteúdos a serem ensinados; às propostas advindas de parcerias firmadas com fundações privadas, em paralelo com a efetivação das orientações curriculares dos estados e municípios; às proposições remanescentes dos Parâmetros Curriculares Nacionais, dentre outros. Isso tudo evidencia que o currículo em ação não se vinculava a uma única origem formal. Nesse amálgama de situações, os professores decidiam "em meio a normas de funcionamento, políticas curriculares, órgão de governo, tradição" (ACOSTA, 2013, p. 190). Não obstante o MEC anunciar que a BNCC não é uma proposta curricular de caráter obrigatório, isso pode ser facilmente contestado, por exemplo, ao se verificar a rigidez imposta no Edital do PNLD 2020, como vimos anteriormente, quanto ao cumprimento integral de suas temáticas, objetos de conhecimento e habilidades.

Ao tratar do conceito de currículo em ação, o documento da BNCC remete à flexibilização que pode ocorrer nas escolas quando estas colocarem em desenvolvimento a Parte Diversificada que é garantida nas Diretrizes Curriculares Nacionais. No entanto, conforme alerta Macedo (2018), a concepção apresentada na BNCC se afasta consideravelmente das vertentes que compreendem o currículo em ação como o vivido no cotidiano das escolas. Segundo esta autora, na proposta da BNCC,

[...] o currículo em ação é uma releitura do currículo formal que ocorre por ocasião de sua implementação. [...] a complementaridade entre currículo prescrito e currículo em ação é da ordem da aplicação, a Base será implementada como currículo em ação (MACEDO, 2018, p. 30).

Retomando a reflexão sobre o que se concretizava no país em termos do currículo em ação na área de História para os Anos Finais do Ensino Fundamental, anteriormente à $\mathrm{BNCC}$, estávamos em pleno movimento de questionamento sobre questões como: o que pode ser considerado um clássico do conhecimento? O que é eleito e quem elege o que se define por patrimônio da humanidade? Que critérios de seleção devem ser acionados, diante da vastidão de conhecimentos acumulados? Tais questões remetem à abordagem do que considerar significativo para ser erigido à categoria de conhecimento a ser ensinado na escola, o denominado "conteúdo escolar", uma ínfima parte do conhecimento produzido coletivamente. 
As escolhas feitas, décadas após décadas, sobre o que ensinar e como ensinar História na escola, e até mesmo sobre a concepção de escola, é produto de um processo seletivo constantemente retroalimentado. A esse movimento Forquin $(1992,1993)$ intitula "cultura escolar", reconhecendo que o estudo de qualquer aspecto relacionado à escola precisa considerar os habitus que impedem o percebimento de uma visão de educação escolar formulada a partir da imposição de grupos que asseguram e legitimam determinados saberes em detrimento de saberes de outros grupos.

A valorização da cultura escolar também é destacada por Acosta (2013) quando da produção de documentos curriculares, ainda que em outros termos. Para esse autor, a tarefa das autoridades educacionais, dos gestores e dos editores, no processo de construção de propostas de socialização de conhecimentos para todos, o que, em último caso, pretende-se que esteja organizado em um currículo, "é reproduzir e não produzir conhecimento" e atuar "em conjunto como agentes reconceitualizantes" (ACOSTA, 2013, p. 190). No entanto, tal papel só pode ser desempenhado se o professor for entendido como principal agente mediador na construção de saberes em sala de aula. Nessa direção, Acosta (2013, p. 190) adverte que, sem ter a escola como ponto de partida, por meio de acordos políticos, pode-se alterar consideravelmente a interpretação da realidade escolar e "a forma e a organização do conhecimento".

O que se ensina e se aprende na escola são escolhas equilibradas entre o que a sociedade preservou e o que ela destruiu para poder se preservar. Assim, a contradição está presente em todas as ações educativas porque estas se situam entre a necessidade de resolver, de forma possível, a equação entre o legitimar determinados saberes, que constituem e explicam a sociedade na qual se vive, e legitimar o extermínio de outros saberes por essa mesma sociedade, no caso, saberes que podem não ser perceptíveis como importantes em uma primeira leitura. A primeira versão da BNCC reconhecia a importância de se considerar outras tantas histórias que não vinham sendo eleitas como conteúdo escolar e reinterpretava os resultados das pesquisas no campo do Ensino de História e no campo historiográfico que recontavam, a partir de outras vozes, processos canônicos de nossa história.

Acosta (2013, p. 191) entende que "os professores fazem política por baixo ou, em outras palavras, rompem com a linha política imposta de cima, ainda que dentro de certos limites". Os limites são identificados, dentre outros, na tradição escolar que mantém várias práticas, mas que também tem espaço para inovações. Nessa perspectiva, a compreensão do que venha a ser a escola comporta diferentes interpretações sobre o que é importante ser alçado à categoria de "conteúdo escolar", pois se compreende que se trata de uma instituição de ensino e aprendizagem de saberes - de todos os tipos e não só 
os denominados escolares -, na qual o conflito entre o velho e o novo se faz constantemente presente, caracterizando o espaço escolar também como espaço de luta pelo poder.

$\mathrm{Na}$ ação, entendemos que o proposto na BNCC e que se concretiza nos livros didáticos por imposição, não abre espaço para esse jogo entre tradição e inovação, pois é por demais tradicional. Sacristán (2013c, p. 262) colabora para explicitarmos nossa hipótese, nestes termos:

Quando se diz que o currículo é "tradicional" em um sentido depreciativo, não o fazemos pretendendo lançar por terra a tradição cultural ou os conteúdos, mas para reclamar o poder, selecionar outros conteúdos e desenvolvê-los como formas de ensinar alternativas às tradicionalistas.

A BNCC não concede espaço para o exercício do poder de escolha aos professores e tal questão pode ser compreendida no contexto da guinada que estamos a assistir em direção a uma sociedade na qual a liberdade não é reconhecida como condição basilar da democracia. Na versão homologada da BNCC, a remoção de todos os conteúdos entendidos como polêmicos ou sensíveis, é representativo de uma ideia de escola pautada na reprodução de saberes e formadora de sujeitos sabedores daquilo que lhes foi permitido saber e não atores interrogantes sobre a própria existência.

Um currículo composto de temas polêmicos com implicações importantes sobre a vida ou a sociedade, sobre o qual podemos ter opiniões distintas e propostas que estimulem a indagação, não é o mesmo que um currículo no qual partimos de conteúdos não problemáticos para aprendê-los de uma maneira não tão viva (SACRISTÁN, 2013c, p. 263).

Estamos a tratar de poder e a escola é uma instituição viva. Finalizamos a escrita desse texto em meio a uma pandemia que mantém as escolas fechadas há mais de seis meses no Brasil. E, guardando as devidas proporções, sempre necessárias quando se fala de um país de dimensões continentais como o Brasil, o desafio é a reinvenção na forma de ensinar e sobre o que ensinar. Em algumas cidades identifica-se o protagonismo dos professores na construção e condução de propostas que visam à permanência da escola na vida dos alunos na tentativa de manter o vínculo (OLIVEIRA, 2020). Tomamos conhecimento de um 
município que não aderiu à proposta de História da $\mathrm{BNCC}$, pois considerou que o programa elaborado em parceria com a universidade local e com uma ampla equipe de professores é mais adequado ao que se almeja ensinar aos jovens e às crianças daquele lugar.

O que podemos aprender com essas histórias? Muito, mas acreditamos que se aliar à rica diversidade que se apresenta nas escolas sobre o currículo em ação, ou sobre os saberes eleitos para comporem a categoria de conteúdo escolar, é um caminho muito mais seguro para consolidar os cenários de uma educação de qualidade.

\section{Indignações finais}

Voltemos à propaganda governamental de divulgação da BNCC aludida no início do artigo e imaginemos o prosseguimento da cena em diferentes escolas brasileiras. Por um lado, tem-se o tema da aula - Cidadania - definido pelo currículo prescrito e tem-se uma aula com procedimentos rigorosamente padronizados a partir da interpretação de tal currículo, representados por meio da exposição oral, da postura docente, da escrita no quadro, sobre os quais se ambiciona uniformidade de norte a sul, leste a oeste do país. Por outro lado, existem as crianças e adolescentes na condição de alunos, mas a propaganda se encerra antes da sua participação na cena escolar. O que viria depois? Segundo Acosta (2013, p. 191), "nem o professor, nem os estudantes podem prever com alguma certeza exatamente o que vai acontecer a seguir". Todavia, na relação imposta entre currículo prescrito e editado, o que se concretizará como currículo em ação estará sempre relacionado com as concepções elaboradas sobre como um sujeito aprende. No caso da propaganda em debate, a partir do momento em que o primeiro estudante contribuir com sua leitura de mundo e formular ideias sobre o que compreende por cidadania, são incontáveis os roteiros que podem ser traçados para o prosseguimento da cena. A tentativa de garantir um único roteiro para todo o país estaria calcada no silenciamento da diversidade que os estudantes trazem para dentro da escola, o que ensejaria a construção de uma narrativa única sobre os conteúdos a serem ensinados.

O perigo de uma aposta em narrativas únicas acerca dos conteúdos escolares é que estas são assentadas em certezas sobre o futuro. Ao prescrever os conteúdos, os procedimentos e definir as competências a serem desenvolvidas a partir de tal currículo, elege-se conhecimentos que são, no contexto de sua formulação, os que se entende como mais adequados no preparo das gerações 
para o amanhã. Entretanto, é fundamental ter em consideração o senso da imprevisibilidade que acompanha o ser humano em todas as sociedades. Podemos nos preparar para um futuro, mas se vamos vivê-lo da forma como planejamos é uma história que se constrói somente no presente.

Assim, qualquer currículo precisa ser compreendido como em movimento, em constante construção. É um risco propor um currículo gerado de um entendimento de escola baseado em uma ou duas funções formativas, pois não se define qual a função do ser humano, para que ele serve ou irá servir, em que irá atuar. Tais respostas são edificadas bloco a bloco no processo de existência que denominamos vida e a escola tem fundamental importância nessa trajetória. Então, concluiríamos que é impossível ter uma base nacional comum que sinalize o que ensinar nas escolas?

Continuamos com a compreensão de que a construção de uma base comum para a área de História seria importante. Ao ler o proposto nas versões anteriores da BNCC, desde o documento "Direitos de Aprendizagem", proposições que foram completamente desidratadas e substituídas na versão final, identificamos em tais documentos uma proposta com movimentos. Arriscou-se eleger como conteúdo escolar as histórias do Brasil narradas a partir de dentro; definiu-se que o indagar sobre as fontes, sobre a realidade, seria um caminho mais promissor para a construção de saberes históricos; apostou-se no protagonismo discente e docente quanto à seleção e organização dos saberes dentro de cada escola. Os envolvidos na construção de tais versões, por compreenderem que ensinar História na escola se efetiva em um amálgama de saberes diversos, indicaram o que é importante para uma base nacional, mas também consideraram o espaço da invenção (ACOSTA, 2013).

A Base que entendíamos importante não dialoga com a finalizada na BNCC. A indignação com a qual finalizamos esse artigo se refere, principalmente, ao ocorrido com o documento da área de História e tudo o que pode vir a acontecer (ou não acontecer) se a proposta ali apresentada se efetivar nas escolas. No entanto, apostamos, como sempre fizemos, na ação docente que, com coragem e ousadia, mantém aceso o poder questionador do ser humano, principalmente das crianças e jovens na condição de alunos, os quais, quando escutados, nos apontam caminhos valiosos para a reinvenção da escola, em que pese as condições adversas pelas quais estamos a passar. Apostamos também que as pesquisas no campo do ensino de História avancem na direção de compreender as lógicas de tantas reinvenções com as quais nos deparamos no cotidiano escolar, pois, segundo Bonafé e Rodríguez (2013, p. 218), "há pouca preocupação em pesquisar as práticas alternativas a esses recursos hegemônicos". Acreditamos, por fim, alicerçadas na força esperançosa de Paulo Freire (2011), que assim transformaremos o que ainda é inédito em viável. 


\section{REFERÊNCIAS}

ACOSTA, Javier Marrero. O currículo interpretado: o que as escolas, os professores e as professoras ensinam? In: SACRISTÁN, José Gimeno (org.). Saberes e incertezas sobre o currículo. Porto Alegre: Penso, 2013. p.188-208.

AGUIAR, Márcia Angela da Silva. Relato da resistência à instituição da BNCC pelo Conselho Nacional de Educação mediante pedido de vista e declarações de votos. In: AGUIAR, Márcia Angela da Silva; DOURADO, Luiz Fernandes (org.). A BNCC na contramão do PNE 2014-2024: avaliação e perspectivas. Recife: ANPAE, 2018. p. 8-22.

BENITO, Agustin Escolano. El manual como texto. Pro-Posições, Campinas, SP, v. 23, n. 3, p. 33-50, 2016.

BONAFÉ, Jaume Martinéz; RODRÍGUEZ, Jesús Rodríguez. O currículo e o livro didático: uma dialética sempre aberta. In: SACRISTÁN, José Gimeno (org.). Saberes e incertezas sobre o currículo. Porto Alegre: Penso, 2013. p. 209-225.

BRASIL. [Constituição (1988)]. Constituição da República Federativa do Brasil. Brasília, DF: Presidência da República, [2020]. Disponível em: http://www.planalto. gov. br/ccivil_03/constituicao/constituicaocompilado.htm. Acesso em: 23 mar. 2021.

BRASIL. Presidência da República. Lei n 9.394, de 20 de dezembro de 1996. Estabelece as diretrizes e bases da educação nacional. Brasília, DF: Presidência da República, 20 dez. 1996. Disponível em: http://www.planalto.gov.br/ccivil_03/leis/L9394.htm. Acesso em: 23 mar. 2021.

BRASIL. Lei $n^{\circ} 10.639$, de 9 de janeiro de 2003. Altera a Lei ${ }^{\circ} 9.394$, de 20 de dezembro de 1996, que estabelece as diretrizes e bases da educação nacional, para incluir no currículo oficial da Rede de Ensino a obrigatoriedade da temática "História e Cultura Afro-Brasileira", e dá outras providências. Diário Oficial da União: seção 1, Brasília, p. 1, 10 jan. 2003. Disponível em: http://www.planalto.gov.br/ccivil_03/leis/2003/110.639. htm. Acesso: 10 abr. 2020.

BRASIL. Lei $n^{\circ} 11.645$, de 10 de março de 2008. Altera a Lei n $^{\circ} 9.394$, de 20 de dezembro de 1996, modificada pela Lei $n^{\circ} 10.639$, de 9 de janeiro de 2003, que estabelece as diretrizes e bases da educação nacional, para incluir no currículo oficial da rede de ensino a obrigatoriedade da temática "História e Cultura Afro-Brasileira e Indígena". Diário Oficial da União: seção 1, Brasília, p. 1, 11 mar. 2008. Disponível em: http://www2. camara.leg.br/legin/fed/lei/2008/lei-11645-10-marco-2008-572787-publicacaooriginal96087-pl.html. Acesso em: 10 abr. 2020.

BRASIL. Presidência da República. Lei $n^{\circ} 13.005$, de 25 de junho de 2014. Aprova o Plano Nacional de Educação - PNE e dá outras providências. Brasília, DF: Presidência da República, 25 jun. 2014. Disponível em: http://www.planalto.gov.br/ccivil_03/_ato20112014/2014/lei/113005.htm. Acesso em: 24 mar. 2021 
BRASIL. Ministério da Educação. Base Nacional Comum Curricular (BNCC), 2017a. Disponível em: http://portal.mec.gov.br/conselho-nacional-de-educacao/ base-nacional-comum-curricular-bncc\#: :text=E\%20no\%20dia $\% 2022 \% 20 \mathrm{de}$, no $\% 20$ $\%$ C3\%A2mbito $\% 20$ da $\% 20$ Educa $\%$ C3\%A7\%C3\%A3o\%20B $\%$ C3\%A1sica. Acesso em: 15 jun. 2020.

BRASIL. Ministério da Educação. Base Nacional Curricular Comum. Educação é a Base. Brasília, DF: MEC: CONSED: UNDIME, 2017b. Disponível em: http:// basenacionalcomum.mec.gov.br/images/BNCC_EI_EF_110518_versaofinal_site.pdf. Acesso em: 18 ago. 2020.

BRASIL. Ministério da Educação. Base Nacional Comum Curricular. [S. l.: s. n. ], 2018a. 1 vídeo (32 seg). Disponível em: https://www.youtube.com/watch?v=Fbz-cpct1W4. Acesso em: 15 jun. 2020.

BRASIL. Ministério da Educação. Edital de Convocação 01/2018 - CGPLI. Edital de Convocação para o Processo de Inscrição e Avaliação de Obras Didáticas para o Programa Nacional do Livro e do Material Didático - PNLD 2020. Brasília, DF, 2018. Disponível em: https://www.fnde.gov.br/programas/programas-do-livro/consultas/editais-programaslivro/item/11555-edital-pnld-2020. Acesso em: 18 ago. 2020.

BRASIL. Ministério da Educação. PNLD 2020: história - guia de livros didáticos. Brasília, DF: MEC: SEB, 2019. Disponível em: https://www.fnde.gov.br/index.php/ programas/programas-do-livro/pnld/guia-do-livro-didatico/item/13410-guia-pnld-2020. Acesso em: 18 ago. 2020.

BRESSANIN, Joelma Aparecida. Educação é a base: a discursividade da propaganda do governo federal. Traços de Linguagem, Cáceres, v. 2, n. 1, p. 22-28, 2018.

FORQUIN, Jean-Claude. Saberes escolares, imperativos didáticos e dinâmicas sociais. Teoria e Educação, Porto Alegre, n. 5, p. 28-49, 1992.

FORQUIN, Jean-Claude. Escola e cultura: as bases sociais e epistemológicas do conhecimento escolar. Porto Alegre: Artes Médicas, 1993.

FRANCO, Aléxia Pádua; SILVA JÚNIOR, Astrogildo Fernandes da; GUIMARÃES, Selva. Saberes históricos prescritos na BNCC para o ensino fundamental: tensões e concessões. Ensino Em Re-Vista, Uberlândia, v. 25, n. Especial, p. 1016-1035, 2018.

FREIRE, Paulo. Pedagogia da esperança: um reencontro com a pedagogia do oprimido. 16. ed. Rio de Janeiro: Paz e Terra, 2011.

HYPOLITO, Álvaro Moreira. Políticas curriculares, Estado e regulação. Educ. Soc., Campinas, v. 31, n. 113, p. 1337-1354, out./dez. 2010.

LOPES, Alice Ribeiro Casimiro. Apostando na produção contextual do currículo. In: AGUIAR, Márcia Angela da Silva; DOURADO, Luiz Fernandes (org.). A BNCC na contramão do PNE 2014-2024: avaliação e perspectivas. Recife: ANPAE, 2018. p. 23-28. 
MACEDO, Elizabeth. "A base é a base”. E o currículo o que é? In: AGUIAR, Márcia Angela da Silva; DOURADO, Luiz Fernandes (org.). A BNCC na contramão do PNE 2014-2024: avaliação e perspectivas. Recife: ANPAE, 2018. p. 28-33.

MACEDO, Elizabeth Fernandes de. Fazendo a Base virar realidade: competências e o germe da comparação. Revista Retratos da Escola, Brasília, DF, v. 13, n. 25, p. 39-58, jan./mai. 2019.

MEZA, Beatriz M. Arrieta de; CEPEDA, Rafael D. Meza. El curriculum nulo y sus diferentes modalidades. Revista Iberoamericana de Educación, Madrid, v. 25, n. Especial, 2001. Disponível em: https://rieoei.org/RIE/article/view/3143. Acesso em: 25 ago. 2020.

OLIVEIRA, Sandra Regina Ferreira (org.). Escolas em Quarentena: o vírus que nos levou para casa. Londrina, PR: Editora Madrepérola, 2020.

SACRISTÁN, José Gimeno. Plano do currículo, plano do ensino: o papel dos professores/ as. In: SACRISTÁN, José Gimeno; GÓMEZ, Ángel I. Pérez. Compreender e transformar o ensino. 4. ed. Porto Alegre: Artmed, 1998. p. 197-232.

SACRISTÁN, José Gimeno (org.). Saberes e incertezas sobre o currículo. Porto Alegre: Penso, 2013a.

SACRISTÁN, José Gimeno. O que significa o currículo? In: SACRISTÁN, José Gimeno. (org.). Saberes e incertezas sobre o currículo. Porto Alegre: Penso, 2013b. p.16-35.

SACRISTÁN, José Gimeno. O currículo em ação: os resultados como legitimação do currículo. In: SACRISTÁN, José Gimeno (org.). Saberes e incertezas sobre o currículo. Porto Alegre: Penso, 2013c. p. 262-280.

SILVA, Tomaz Tadeu da. Documentos de Identidade: uma introdução às teorias do currículo. 3. ed. Belo Horizonte: Autêntica, 2010.

Texto recebido em 04/10/2020.

Texto aprovado em 09/02/2021. 